GRADIATION\&APPLICATIONS

ISSN 2466-4294 (online) | rad-journal.org

Vol. 2 | Issue 1 | pp. $31-34$

doi: 10.21175/RadJ.2017.01.007

Original research paper

\title{
ASSESSMENT OF THE EXPOSURE OF RADIATION WORKERS IN NUCLEAR MEDICINE WITH SOME RESULTS FROM THE CZECH REPUBLIC*
}

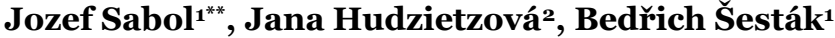 \\ ${ }^{1}$ Faculty of Security Management, PACR in Prague, Prague, Czech Republic \\ ${ }^{2}$ Faculty of Biomedical Engineering of CTU in Prague, Prague, Czech Republic
}

\begin{abstract}
During the manipulation with radiopharmaceuticals, workers in nuclear medicine always receive certain exposure which is continuously monitored and strictly controlled by relevant national regulatory authorities. This exposure should be minimized following the ALARA principle and be at all times below prescribed limits or reference levels. The paper presents some results of the assessment of radiation doses of nuclear medicine personnel where special attention is paid to the exposure of the extremities and to the skin of hands in particular. It has been observed that the skin dose of some workers may exceed the relevant annual dose limit and therefore some measures should be adopted to reduce this exposure. The situation in the Czech Republic related to the radiation burden of workers in nuclear medicine is outlined and conclusions discussed.
\end{abstract}

Key words: Radiation exposure, nuclear medicine, radiopharmaceuticals, dose limit, skin dose, Czech Republic

\section{INTRODUCTION}

Nuclear medicine is based on the use of open radioactive sources or rather chemicals (labelled by suitable radionuclides), called radiopharmaceuticals, mainly for very sophisticated diagnostic examinations, and to a certain extent also for radiotherapy treatment of specific cancers. The diagnostic information is obtained from imaging the distribution of radiopharmaceuticals in relevant body organs and tissues. The results, derived from the molecular image created through the detection of radiation emitted by radioactive atoms spread within the body, reflect functional processes rather than anatomic configuration.

The use of modern radiopharmaceuticals is exceptionally valuable in obtaining information about the initial stage of cancer as well as heart and brain diseases [1]. It is often practically impossible to obtain such diagnostic evidence by other means, which makes nuclear medicine a unique medical modality.

Basically, any nuclear medicine study involves injecting a radiopharmaceutical containing a gamma or positron emitting radionuclide into the patient. Naturally, this radionuclide always irradiates not only the patient but it may also contribute to the exposure of any person close to the patient.

The staff of nuclear medicine clinics or departments always receives some doses acquired during the handling and manipulation of radiopharmaceuticals.
This includes their preparation and administration to the patients.

Nuclear medicine workers are exposed by penetrating gamma radiation, which results in wholebody exposure, as well as by beta particles or positrons affecting mainly the extremities, namely the skin of the hands. Of course, the skin is also partially exposed to gamma radiation and, on the other hand, interacting positrons eventually produce energetic photons of electromagnetic radiation, which makes a certain additional contribution to the total effective dose of a worker.

\section{RADIATION PROTECTION REQUIREMENTS}

In general, the main aim of radiation protection is to ensure the adequate safety of workers, patients, and the general population as well as the environment against any harmful effects of ionizing radiation. In most cases the health effects are very low and the associated risk is lower or comparable with the risk encountered in most industries or even in our everyday life. It is only in cases of incidents or accidents that the radiation exposure may reach higher levels and where visible detrimental effects occur [2].

While stochastic effects appear with some probability proportional to the exposure, the deterministic effects always occur in cases where the dose exceeds a certain threshold. This level varies with the type of tissues or organs. The level of the

\footnotetext{
* The paper was presented at the Fourth International Conference on Radiation and Applications in Various Fields of Research (RAD 2016), Niš, Serbia, 2016.

jozef.sabol@gmail.com
} 
manifestation of deterministic effects depends also on the characteristics of radiation delivering doses. Usually, the higher the ionization density the radiation can produce, the lower this level is

The use of medical imaging is rising, and approximately 3.3 billion of the 5 billion imaging examinations performed worldwide use ionizing radiation. Thus, diagnostic imaging contributes to the majority of artificial radiation exposure to humans. Several medical imaging disciplines and specialties use ionizing radiation, including general diagnostic radiology, nuclear medicine, computed tomography (CT), fluoroscopy, and interventional radiology [3].

The exposure to the population due to the use of ionizing radiation in medicine, including radioactive sources in nuclear medicine, has multiplied during the last 20 years to as high as 6 times in developed countries. About twenty years ago the contribution from medical practice was around $0.3 \mathrm{mSv}$; now it is comparable to the exposure to radon or even higher. How much is the exposure to radon and why do you include it? For example, in the USA the population exposure reached more than $3 \mathrm{mSv}$ per year [4].

Data from last few years in the national surveys reported indicate that the use of PET and combined $\mathrm{PET} / \mathrm{CT}$ scans is rapidly increasing [5]. In view of the relatively high effective doses for these procedures (particularly PET/CT), these examinations are likely to make a major contribution to the collective dose from nuclear medicine in most developed countries in the near future.

Because of the higher number of medical examinations by means of PET/CT [5] which are mainly responsible for the doses from man-made sources, there is also an increase in the exposure of those who are working with these sources.

The increased new modalities in nuclear medicine, especially those related to PET-imaging, require the use of a variety of innovative radiopharmaceuticals, thereby causing a need to develop and adopt more careful radiation protection procedures in order to satisfy relevant standards as to the relevant dose limits, which specify the upper annual levels of the exposure of the whole-body $(20 \mathrm{mSv})$ and the equivalent dose to the skin $\left(500 \mathrm{mSv}\right.$ average over the area of $1 \mathrm{~cm}^{2}$ of the most exposed place on the surface of the hands).

This expansion of the field results in an increasing number of nuclear medicine staff who require specific training in order to learn how to protect themselves and others. The exposure of the staff can be considered as a sign reflecting the compliance with the regulatory requirements.

Traditionally, diagnostic radiology, nuclear medicine, and radiation therapy were separate, with little or no combined usage. This has recently changed, with the so-called hybrid imaging systems involving both diagnostic radiology and nuclear medicine expertise, and with the planning, guidance and verification stages of radiation therapy increasingly involving both imaging and radiation therapy expertise.

Medical uses of ionizing radiation involve all three categories of exposure: occupational exposure for those involved in the performance of radiological procedures; medical exposure, primarily for the patients undergoing the radiological procedures but also for care-givers and for volunteers subject to exposure as part of a programme of medical research; and public exposure for members of the public, such as in waiting rooms.

Medical exposure differs from occupational and public exposure in that persons (primarily patients) are deliberately, directly, and knowingly exposed to radiation for their benefit. In medical exposures applying a 'dose limit' is inappropriate as it may limit the benefit for the patient; consequently, only two of the radiation protection principles apply - justification and optimization.

In nuclear medicine so-called reference levels have been introduced in order to keep patient exposure as low as is possible under the circumstances. From the philosophy of radiation protection it is clear that it is not enough to satisfy the relevant dose limits or reference levels, but to try to minimize the doses to as low as readily achievable.

\section{DOSES OF WORKERS IN THE CZECH REPUBLIC}

The exposure of hands of workers is mainly due to the direct contact with the radiopharmaceuticals (Fig. 1) during their preparation and administration.

The whole-body dose of workers is owed to assisting and escorting patients. The whole body dose of workers is measured with special personal dosimeters, usually thermoluminiscent dosimeters (TLDs), the results of which are interpreted in terms of the personal dose equivalent $-\mathrm{H}_{p}(10)$ - approximating the effective dose $(E)$ of a monitored person.

The monitoring of extremities, in fact, the skin dose on the surface of the hands of workers, also relies on TLDs, which are much thinner in this case in order to produce the results in the quantity of the personal dose equivalent $\mathrm{H}_{p}(0.07)$. This quantity is then used to assess the equivalent dose in the skin $\mathrm{H}_{\text {skin }}$.

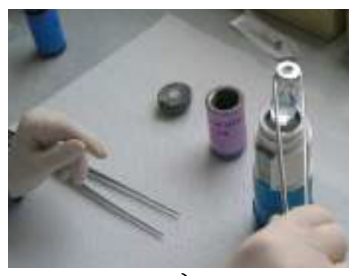

a)

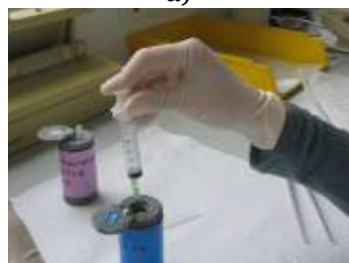

c)

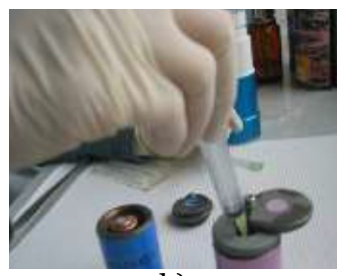

b)

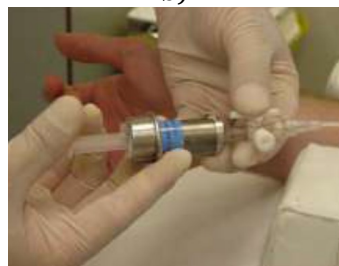

d)
Figure 1. Main procedures during which workers are exposed: a) during the manipulation of the generator, b) during via elution, c) during the labelling of the vial containing the radiopharmaceuticals, d) during administration. 
As to the exposure of radiation workers in nuclear medicine in the Czech Republic, there are nearly 50 nuclear medicine clinics, departments and laboratories engaged in the use of radiopharmaceuticals and other radioactive material.

The situation in the Czech Republic regarding the whole-body exposure of radiation workers in nuclear medicine is illustrated in Fig. 2 (based on [6]). The annual mean effective dose of these workers was slightly above $0.5 \mathrm{mSv}$. As to the annual effective dose, the relevant dose limit is met. The difficulties may cause some concern in the case of the exposure of extremities where appropriate correction factors should be used. These factors correspond to the ratio between the equivalent dose to the skin at the location with 3 maximum exposure to the result obtained from TLDs which are obviously not position at such location.

\section{SPECIFIC PROBLEMS OF SKIN EXPOSURE}

Since skin exposure presents a special case as regards achieving compliance with the regulatory requirements, some more detailed measurements have been carried out in selected nuclear medicine clinics in the Czech Republic [7]. The measurements were carried out using special TLDs, the readings of which could be interpreted as the equivalent dose to the skin.

In order to find out more details as to the work habits and differences between individual workers performing the same operations, some video shots and photos were taken during the measurement where special gloves with TLDs were used.

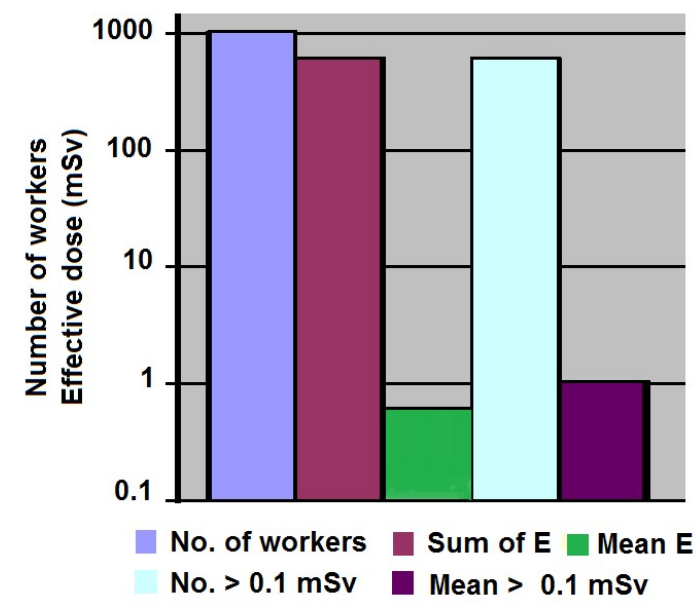

Figure 2. The annual $E$ of workers in nuclear medicine showing the number of workers, the dose $E$, the average dose $E$, the number of workers with $\mathrm{E}$ above $0.1 \mathrm{mSv} / \mathrm{y}$, and the average $E$ of workers exposed to the dose above $0.1 \mathrm{mSv} / \mathrm{y}$.

The measurements were conducted at the two nuclear medicine clinics that are located within two large hospitals. Both clinics are engaged in a variety of PET/CT examinations, including those based on the use of radiopharmaceuticals labelled as ${ }^{18} \mathrm{~F}$. In total, 64 measurements were performed.

The workers were monitored using cotton gloves with 12 pairs of TLDs glued to selected locations in order to map the distribution of the personal dose equivalent on the skin of the hands. Three measurements on each worker were performed, where every measurement included 25 operations (preparations and administration).

One can estimate that the skin exposure of $60 \%$ (preparation and application at Clinic I) of them will fall in the range between 150 and $500 \mathrm{mSv}$, i.e. the equivalent dose to the skin will exceed three-tenths of the relevant dose limit. From these results, it can be assumed that $40 \%$ of workers (application at Clinic I) may exceed the annual dose limit for exposure to the skin (500 mSv/ y) [5].

On the other hand, the results of monitoring suggest that all workers at Clinic II would receive a total skin equivalent dose of $150 \mathrm{mSv} / \mathrm{y}[7,8]$.

The comparison of results of this study with the results of the study conducted under the ORAMED project [9,10] (Fig. 3) confirms some consistency with respect to the possible exceeding of the reference level or dose limit and at the same time the fact that there is a wide range of skin doses among individual workers. This is why the studies of the exposure to workers have to continue in order to obtain reliable results based on which such exposure can be optimized.

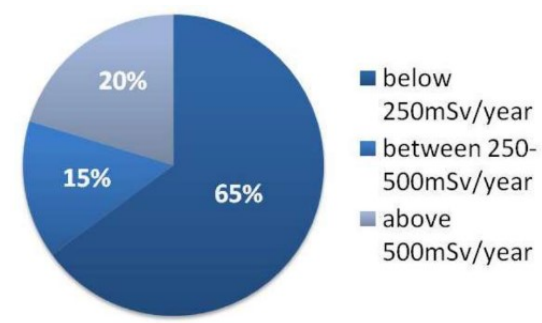

Figure 3. The findings of the ORAMED study, which included seven European countries, illustrates that the skin exposure can exceed the relevant dose limit in about $20 \%$ of radiation workers in nuclear medicine [7].

\section{CONCLUSION}

In general, it has been recognized that current nuclear medicine is one of the best examples of the successful peaceful use of radiation and nuclear technologies. This is why all countries promote the development of this powerful modality, which has become irreplaceable in many imaging and therapeutic applications as a sophisticated tool for the clinical management of specific types of diseases.

The ever increasing number of nuclear medicine procedures requires the introduction of reliable methods that ensure the adequate protection of workers and patients as well as members of the public. It is therefore of paramount importance to maintain a strict control of exposure, which is especially significant for nuclear medicine physicians, physicists, technologists as well as nurses who are handling radioactive substances in large quantities or take care of radioactive patients. The protection of these personnel has to be monitored using appropriate dosimeters in order to assess whole-body and skin exposure. 
J. Sabol et al., Assessment of the Exposure of Radiation Workers..., Rad. Applic., 2017, 2, 1, 31-34

The paper summarised some preliminary results of the assessment of the exposure of the hands of workers manipulating ${ }^{18} \mathrm{~F}$-labelled radiopharmaceuticals based on personal monitoring at two nuclear medicine clinics in the Czech Republic. The results have shown that out of all 21 workers monitored, $\sim 43 \%$ (preparation and applications of radiopharmaceuticals) may reach an exposure equal to three-tenths of the annual dose limit to the skin. At the same time, it can also be concluded that in $\sim 10 \%$ cases of workers, the relevant dose limit may be exceeded.

The results obtained at two nuclear medicine clinics in the Czech Republic have shown that exposure of the workers differs mainly due to their different approach in handling radioactive material (the preparation of radiopharmaceutical in dispensing stations provided from different suppliers). The dissimilarity was also in the administration of radiopharmaceuticals - this was performed in a tungsten shielding with and sometime without the use of cannula. In addition, from our video shots, we could notice that there were visible dissimilarities as to the handling radioactive sources among individual workers involved in the same operations even at the same workplace. This is why it would be desirable to pay more attention to the training of all workers in order to follow and unify procedures, which should be optimised in order to further minimise the exposure.

The use of suitable technological equipment (semiautomatic dispensing devices or applicators) [11 - 13], as well as appropriate protective equipment recommended by manufacturers, can certainly lead to dose reduction. The results presented also demonstrate the need for more nuclear clinics to be included in a similar survey in order to obtain a more comprehensive overview of the situation related to the exposure of the nuclear medicine personnel in the country. Everything suggests that more attention should be paid to the skin doses to the extremities, including the introduction of the appropriate correction factors (representing the ratio between the maximum exposure and the exposure read by the finger dosimeter) in order to assess more realistically compliance with regulatory requirements following an analogous approach as recommended in the ORAMED studies. This study recommended the use of the factor of 6 provided that the finger dosimeter was positioned at the forefinger root.

Acknowledgement: The work was partially supported by the project SGS13/161/OHK4/2T/17.

\section{REFERENCES}

1. International Atomic Energy Agency. (2016). IAEATECDOC-1782 Good practice for introducing radiopharmaceuticals for clinical use. Retrieved from: http://wwwpub.iaea.org/MTCD/Publications/PDF/TE1782 web.pdf Retrieved on: Feb. 12, 2016.

2. International Commission on Radiological Protection. (2007). Publication 103: The 2007 recommendations of the International Commission on Radiological Protection"

DOI: $10.1016 /$ j.icrp.2007.10.003

PMID: 18082557

3. Sources and Effects of Ionizing Radiation, UNSCEAR 2008 Report to the General Assembly with Scientific Annexes, vol. 1, United Nations, New York, 2010 Retrieved from: http://www.unscear.org/docs/reports/2008/o986753_Report 2008 Annex B.pdf Retrieved on: Apr. 10, 2016.

4. D. Shauer, O. W. Linton, "National Council on Radiation Protection and Measurements Report shows substantial medical exposure increase," Radiology, vol. 253, no. 2, pp. 293-296, 2006.

DOI: $10.1148 /$ radiol.2532090494

PMid: 19864524

5. O. Bělohlávek, J. Potreba: PET/CT. The Czech Nuclear Medicine Society (ČSNM)

Retrieved from:

http://csnm.cz/about-domain/pet-ct-need Retrieved on: Apr. 10, 2016.

6. K. Petrová, Personal monitoring and health supervision on radiation workers, State Office for Nuclear Safety, Prague 2014 (in Czech).

7. J. Hudzietzová, et al., "Assessment of the local exposure of skin on hands of nuclear medicine workers handling ${ }^{18}$ F-labelled radio-pharmaceuticals: Preliminary Czech study," Radiat. Prot. Dosimetry, vol. 171, no. 4, pp. 445-452, 2016.

DOI: $10.1093 / \mathrm{rpd} / \mathrm{ncv} 441$ PMid: 26503855

8. J. Hudzietzová et al., "The radiation exposure of workers' hands during the preparation and administration of radiopharmaceuticals labelled with a radionuclide ${ }^{18}$ F," Ces. Radiol, vol. 68, no. 4, pp. 318 322, 2014.

9. European Radiation Dosimetry Group e. V., ORAMED: Optimization of Radiation Protection of Medical Staff, Chapter 4: Extremity dosimetry in nuclear medicine, EURODAS Report 2012-02. Braunschweig, Germany, 2012.

Retrieved from:

http://www.eurados.org/ /media/Files/Eurados/docu ments/EURADOS Report 201202.pdf

Retrieved on: Jan. 20, 2016.

10. F. Vanhavere, "Assessing and reducing exposures to nuclear medicine staff," ORAMED, Seventh Framework Programme, 2008-2011.

Retrieved from:

https://rpop.iaea.org/RPOP/RPoP/Content/Document s/Whitepapers/conference/S3-Vanhavere-Assessingand-reducing-exposures.pdf Retrieved on: Apr. 15, 2016.

11. R. M. Sánchez et al., "Evaluation of an automated FDG dose infuser to PET-CT patients," Radiation Prot. Dosimetry, vol. 165, no. 1-4, pp. 457-460, 2015.

DOI: $10.1093 / \mathrm{rpd} / \mathrm{ncvo77}$ PMid: 25821215

12. P. Covens et al., "The introduction of automated dispensing and injection during PET procedures: A step in the optimization of extremity doses and whole-body doses of nuclear medicine staff," Radiation Prot. Dosimetry, vol. 140, pp. 250 - 258, 2014.

DOI: $10.1093 / \mathrm{rpd} / \mathrm{ncq} 110$

PMid: 20335185

13. V. Antic et al., "Radiation exposure to nuclear medicine staff involved in PET/CT practice in Serbia," Radiation Prot. Dosimetry, vol. 162, pp. 577 - 585, 2014.

DOI: $10.1093 / \mathrm{rpd} / \mathrm{ncuoO} 1$

PMid: 24464817 